\title{
The Impact of Chronic Repetitive Leg Ischemia on Left Ventricular Function and Severity of Coronary Atherosclerosis in Patients with Acute Coronary Syndrome
}

\author{
Mutlu Gungor ${ }^{\mathrm{a}}$ Erkan Yildirim ${ }^{\mathrm{b}}$ \\ a Department of Cardiology, Memorial Sisli Hospital, Istanbul, and bepartment of Cardiology, Gulhane Research \\ and Training Hospital, Ankara, Turkey
}

\section{Significance of the Study}

- In this study, the coexistence of peripheral arterial disease (PAD) and coronary artery disease (CAD) was associated with preserved left ventricular (LV) function at the early stage of the diagnosis of acute coronary syndrome, and was also associated with a more extensive coronary atherosclerosis and renal dysfunction. The protective effect of remote ischemic preconditioning (RIPC) triggered by intermittent claudication secondary to PAD might have a protective effect on LV function in patients with CAD. Hence, patients with CAD could benefit from RIPC.

\section{Keywords}

Peripheral arterial disease - Coronary artery disease .

Ventricular dysfunction - Remote ischemic preconditioning

\begin{abstract}
Objective: The purpose of this study was to assess the impact of the presence of peripheral arterial disease (PAD) on left ventricular (LV) function in patients with coronary artery disease (CAD) presenting with acute coronary syndrome (ACS). Subjects and Methods: The medical records of the patients who were referred to Ankara Bayindir Hospital, Ankara, Turkey, due to a first episode of ACS were reviewed. Patients with concomitant PAD and CAD (group 1) were compared with those who had CAD only (group 2). The Mann-Whitney $U$ and $X^{2}$ tests were used to compare continuous and categorical variables, respectively. Results:
\end{abstract}

\section{KARGER}

E-Mail karger@karger.com www.karger.com/mpp
(C) 2017 The Author(s)

Published by S. Karger AG, Basel

\section{Karger}

open access

This is an Open Access article licensed under the Creative Commons Attribution-NonCommercial-4.0 International License (CC BY-NC) (http://www.karger.com/Services/OpenAccessLicense), applicable to the online version of the article only. Usage and distribution for commercial purposes requires written permission.
Baseline demographic data of 53 patients with PAD + CAD (42 men and 11 women; mean age $62.5 \pm 9.5$ years) and a group of 60 patients with CAD only ( 41 men and 19 women; mean age $59.9 \pm 9.8$ years) were similar, except for the serum creatinine level which was higher in group 1 than in group $2(1.32 \pm 0.34$ vs. $1.03 \pm 0.22 \mathrm{mg} / \mathrm{dL}, p<0.001)$. Patients with CAD + PAD had significantly higher Gensini scores $(62.6 \pm 19.7$ vs. $41.4 \pm 26.8, p=0.004)$ and more 3 -vessel disease than patients with CAD alone ( 62.2 vs. $31.6 \%$, $p<0.045)$. There was a significant difference between the 2 groups regarding the LV ejection fraction at the time of the diagnosis $(52.0 \pm 8.2 \%$ in the CAD + PAD group and $43.7 \pm$ $13.3 \%$ in the $C A D$-alone group; $p=0.017)$. Conclusion: $C A D$ concomitant with PAD was associated with preserved LV function at early stages of diagnosis in patients with ACS.

(C) 2017 The Author(s) Published by S. Karger AG, Basel
Erkan Yildirim, MD

Staff Cardiologist, Department of Cardiology

Gulhane Research and Training Hospital

TR-06018 Etlik, Ankara (Turkey)

E-Mail dr_erkanyildirim@yahoo.com.tr 


\section{Introduction}

Atherosclerosis is a diffuse process that may affect different vascular beds, and coronary artery disease (CAD) and peripheral arterial disease (PAD) overlap considerably. Because both diabetes mellitus and PAD are accepted as CAD equivalents [1], the coexistence of PAD and $\mathrm{CAD}$ is associated with more extensive atherosclerosis and poor long-term survival than CAD only $[2,3]$. However, in some reports, short-term cardiovascular outcomes in patients with PAD have been similar to in CAD patients without $\mathrm{PAD}$, particularly in the early postoperative period $[4,5]$. In numerous studies [6-9], it has been suggested that transient brief episodes of intermittent ischemia of the leg, experimentally and clinically known as remote ischemic preconditioning (RIPC), can provide potent myocardial protection. In this study, we hypothesized that RIPC triggered by intermittent claudication secondary to PAD might show a protective effect on left ventricular (LV) function in patients with CAD at the early stage of the diagnosis. Therefore, our aim was to evaluate the impact of chronic repetitive leg ischemia on $\mathrm{LV}$ function and the severity of CAD in patients with acute coronary syndrome (ACS).

\section{Subjects and Methods}

The medical records of the patients who were referred to Ankara Bayindir Hospital, Ankara, Turkey for a first episode of ACS from January 2002 to May 2015 were reviewed. Those who had concomitant CAD + PAD (group 1; 53 patients) were compared to those with $\mathrm{CAD}$ alone as the control (group 2; 60 patients). All patients in group 1 had a history of intermittent claudication, digital subtraction angiographic evidence of stenosis in the leg arteries below the aortic bifurcation or the abdominal aorta, and concomitant coronary angiographic evidence of CAD. The demographic variables, medical history, clinical features, and angiographic data were obtained from the medical and angiographic records. Serum levels of total cholesterol, high-density lipoprotein and low-density lipoprotein cholesterol, triglycerides, and creatinine levels were also obtained from the medical records. The LV ejection fraction (LVEF) was analyzed by echocardiogram. To estimate the extent of the CAD, 2 experienced observers (E.Y. and M.G.), blinded to the patient's clinical data, visually analyzed the coronary angiograms of all patients from angiographic recordings in a random sequence. The CAD was defined as a $50 \%$ reduction in the internal diameter of the left anterior descending artery, right or circumflex coronary artery, or their primary branches. The CAD extension was classified according to the standard method into 1-, 2-, or 3-vessel disease and the Gensini score was calculated for each patient [10]. The Gensini score was computed by assigning a severity score to each coronary stenosis based on the degree of luminal narrowing and its geographic importance. The study was conducted in accordance with the Declaration of Helsinki and the local ethics committee approved the study protocol.
Statistical Analyses

Data were analyzed with the Statistical Package for the Social Sciences (SPSS) v16 (SPSS Inc., Chicago, IL, USA) software. Continuous variables were expressed as mean \pm standard deviation and categorical variables as numbers and percentages. The MannWhitney $U$ test results were used for the comparison of continuous variables. The $\chi^{2}$ test was used for the comparison of categorical variables. Differences were considered statistically significant when the $p$ value was $<0.05$.

\section{Results}

Baseline demographic data were similar in the 2 groups, except for the serum creatinine level which was higher in group 1 than in group $2(1.32 \pm 0.34$ vs. $1.03 \pm$ $0.22 \mathrm{mg} / \mathrm{dL}, p<0.001$ ) (Table 1). Patients with concomitant CAD + PAD had significantly higher Gensini score $(62.6 \pm 19.7$ vs. $41.4 \pm 26.8, p=0.004)$ and more 3 -vessel disease $(62.2$ vs. $31.6 \%, p<0.045)$ than patients with CAD alone. Group 1 also had significantly higher LVEF than group $2(52.0 \pm 8.2$ vs. $43.7 \pm 13.3, p=0.017)$. In the follow-up records of May 2015, 4 patients in group 1 (2 from chronic renal failure, 1 with ACS, and 1 with progressive LV dysfunction), and 1 in group 2 (from ACS) had died.

\section{Discussion}

In this small retrospective study, the coexistence of PAD and CAD was associated with preserved LV function at the early stage of the diagnosis of ACS, but it was associated with more extensive coronary atherosclerosis and renal dysfunction than in patients with $\mathrm{CAD}$ alone. These findings could be due to silent or atypical myocardial ischemia/infarction, believed to be the major cause of morbidity among people suffering from diabetes, due to a condition called diabetic neuropathy which can cause difficulties and a delay regarding a true cardiac diagnosis. Whereas the intermittent claudication limiting ambulation might have been an early symptom in seeking early medical attention and the patients therefore received medical treatment early, diabetic patients who did not undergo could have a delayed presentation due to silent myocardial ischemia/infarction, which leads to worse initial LV function than in patients with intermittent claudication $[8,9]$.

RIPC could have a protective effect on LV ventricular function. Numerous studies have shown that brief transient episodes of intermittent ischemia of the arm or leg 
Table 1. Baseline demographic features and results

\begin{tabular}{lccc}
\hline & $\begin{array}{c}\text { Group 1 } \\
(n=53)\end{array}$ & $\begin{array}{l}\text { Group 2 } \\
(n=60)\end{array}$ & $p$ value \\
\hline Age, years & $62.5 \pm 9.5$ & $59.9 \pm 9.8$ & 0.360 \\
Male & $42(79.2)$ & $41(68.3)$ & 0.508 \\
Female & $11(20.7)$ & $19(31.6)$ & \\
History of anterior myocardial infarction & $22(41.5)$ & $25(41.6)$ & 1.00 \\
Hypertension & $33(62.2)$ & $30(50.0)$ & 0.552 \\
Diabetes mellitus & $20(37.7)$ & $28(46.6)$ & 0.765 \\
Smoking & $35(66.0)$ & $32(53.3)$ & 0.547 \\
Total cholesterol, mg/dL & $213.6 \pm 59.4$ & $216.3 \pm 37.5$ & 0.856 \\
LDL-cholesterol, mg/dL & $138.6 \pm 57.3$ & $130.2 \pm 31.1$ & 0.536 \\
HDL-cholesterol, mg/dL & $37.4 \pm 10.4$ & $42.5 \pm 10.9$ & 0.115 \\
Triglyceride, mg/dL & $219.3 \pm 100.7$ & $205.9 \pm 105.7$ & 0.661 \\
Creatinine, mg/dL & $1.32 \pm 0.34$ & $1.03 \pm 0.22$ & 0.001 \\
1-vessel disease & $11(20.7)$ & $16(26.6)$ & 0.734 \\
2-vessel disease & $9(16.9)$ & $25(41.6)$ & 0.103 \\
3-vessel disease & $33(62.2)$ & $19(31.6)$ & 0.045 \\
Gensini score & $62.6 \pm 19.7$ & $41.4 \pm 26.8$ & 0.004 \\
LVEF, \% & $52.0 \pm 8.2$ & $43.7 \pm 13.3$ & 0.017 \\
\hline
\end{tabular}

Values are expressed as $n(\%)$ or means \pm SD. LVEF, left ventricular ejection fraction; LDL, low-density lipoprotein; HDL, high-density lipoprotein.

could provide potent myocardial protection experimentally and clinically. It has been reported that PAD is an independent risk factor for late mortality only after coronary artery bypass grafting $[4,5]$. All these studies revealed that RIPC might play an important role in cardioprotection in patients with PAD. Patients with chronic intermittent claudication due to PAD experience aching muscles during walking secondary to ischemia, and this ischemia may be responsible for the protective effect on LV function by triggering RIPC mechanisms. Kharbanda et al. [11] suggested that transient limb ischemia releases some neurogenic and circulating factors that induce protection against myocardial ischemia and reperfusion injury across species. In order to improve the long-term outcome for PAD patients, we need aggressive therapy for atherosclerosis. Regular physical activity/walking is recommended in patients with PAD. It has been shown that regular exercise has an important beneficial impact on functional capacity and the prevention of PAD and CAD, particularly through the beneficial effects on endothelial function, antioxidant systems, heatshock protein expression, and vascular remodeling [12, 13]. Supervised physical training, besides being the most effective means to increase walking ability, also proved to have a benefit on LV contractility. It is probable that moderate hemodynamic stress reduces the levels of inflammatory markers and increases flow-mediated vasodilation by ischemic preconditioning. In patients with CAD, it has been shown that increased walking ability is associated with improved LVEF $[14,15]$. The recently published study of Bøtker et al. [16] has provided a promising result, showing that RIPC before hospital admission in the setting of ACS protects LV function. In previous studies demonstrating that RIPC has a protective effect on LV function, the RIPC was mostly provided artificially. However, our study showed that, most probably by a similar mechanism, RIPC triggered by intermittent claudication secondary to PAD can have a protective effect on LV function in patients with CAD. Consistent with the previous studies, our study supports that patients with CAD may benefit from RIPC. Although the precise mechanisms are not fully defined, RIPC can be a very important clinical tool in the management of CAD. However, the widespread adoption of RIPC will require demonstration of effect in large, unselected, cohort studies.

The limitations of this study included its retrospective and single-center design, its relatively small sample size, and the interval to balloon time and onset of the infarct were not evaluated. 


\section{Conclusion}

In this study, at the early stages of diagnosis in patients with ACS, the coexistence of PAD with CAD was associated with preserved LV function when compared to the patients with CAD alone. The RIPC triggered by chronic repetitive claudication may have a protective effect on $\mathrm{LV}$ function. However, further prospective trials evaluating the clinical importance of RIPC are needed to confirm this hypothesis.

\section{References}

1 Golomb BA, Dang TT, Criqui MH: Peripheral arterial disease: morbidity and mortality implications. Circulation 2006;114:688-699.

2 Makowsky MJ, McAlister FA, Galbraith PD, et al; Alberta Provincial Program for Outcome Assessment in Coronary Heart Disease (APPROACH) Investigators: Lower extremity peripheral arterial disease in individuals with coronary artery disease: prognostic importance, care gaps, and impact of therapy. Am Heart J 2008;155:348-355.

3 Elbasan Z, Şahin DY, Gür M, et al: Aortic distensibility and extent and complexity of coronary artery disease in patients with stable hypertensive and nonhypertensive coronary artery disease. Med Princ Pract 2013;22: 260-264.

4 Chu D, Bakaeen FG, Wang XL, et al: The impact of peripheral vascular disease on longterm survival after coronary artery bypass graft surgery. Ann Thorac Surg 2008;86: $1175-1180$.

5 van Straten AH, Firanescu C, Soliman Hamad MA, et al: Peripheral vascular disease as a predictor of survival after coronary artery bypass grafting: comparison with a matched general population. Ann Thorac Surg 2010;89:414420.
6 Shimizu M, Tropak M, Diaz RJ, et al: Transient limb ischaemia remotely preconditions through a humoral mechanism acting directly on the myocardium: evidence suggesting cross-species protection. Clin Sci (Lond) 2009;117:191-200.

7 Loukogeorgakis SP, Williams R, Panagiotidou AT, et al: Transient limb ischemia induces remote preconditioning and remote postconditioning in humans by a K(ATP)channel dependent mechanism. Circulation 2007;116:1386-1395.

$8 \mathrm{Li} \mathrm{CM}$, Zhang XH, Ma XJ, et al: Ischemic postconditioning protects myocardium from ischemia-reperfusion injury. Scand Cardiovasc J 2006;40:312-317.

9 Shimizu M, Konstantinov IE, Kharbanda RK, et al: Effects of intermittent lower limb ischaemia on coronary blood flow and coronary resistance in pigs. Acta Physiol (Oxf) 2007; 190:103-109.

10 Gensini GG: A more meaningful scoring system for determining the severity of coronary heart disease. Am J Cardiol 1983;51:606.

11 Kharbanda RK, Nielsen TT, Redington AN: Translation of remote ischaemic preconditioning into clinical practice. Lancet 2009; 374:1557-1565.
12 Barak S, Stopka CB, Archer Martinez C, et al: Benefits of low-intensity pain-free treadmill exercise on functional capacity of individuals presenting with intermittent claudication due to peripheral arterial disease. Angiology 2009; 60:477-486.

13 Leung FP, Yung LM, Laher I, et al: Exercise, vascular wall and cardiovascular diseases: an update (Part 1). Sports Med 2008;38:1009_ 1024.

14 Andreozzi GM, Leone A, Laudani R, et al: Acute impairment of the endothelial function by maximal treadmill exercise in patients with intermittent claudication, and its improvement after supervised physical training. Int Angiol 2007;26:12-17.

15 Naghshin J, McGaffin KR, Witham WG, et al: Chronic intermittent hypoxia increases left ventricular contractility in C57BL/6J mice. J Appl Physiol 2009;107:787-793.

16 Bøtker HE, Kharbanda R, Schmidt MR, et al: Remote ischaemic conditioning before hospital admission, as a complement to angioplasty, and effect on myocardial salvage in patients with acute myocardial infarction: a randomised trial. Lancet 2010;375:727-734. 